\title{
EDITORIAL
}

\section{Una consideración ética de la deuda internacional}

La Comisión Pontificia "lustitia et Pax" presentó a la opinión pública mundial el día 27 de enero pasado el documento Al servicio de la comunidad humana: una consideración ética de la deuda internacional.

Ya en la presentación del mismo el cardenal Etchegaray, presidente de la Comisión, ofrece un principio ético eficiente y operativo: "El ser" vicio de la deuda no puede ser satisfecho al precio de una asfixia de la economia de un pais. Ningún gobierno puede exigir moralmente a su pueblo que sufra privaciones incompatibles con la dignidad de las personas." Este principio creemos legitima posiciones como la del presidente Alfonsín, cuando decia que "la deuda no debe ser pagada con el hambre de los argentinos"; la del presidente La Madrid, cuando afirmaba que la deuda ha de ser devuelta de acuerdo con la capacidad de la economía mejicana; la del presidente Alán García, en su propósito de destinar al pago del servicio anual de la deuda lamortización e intereses) sólo el importe del 10 por 100 de las exportaciones anuales del Perú.

Los principios éticos orientadores, que el documento enumera, son éstos: crear nuevas solidaridades, aceptar la corresponsabilidad, establecer relaciones de confianza, saber compartir esfuerzos y sacrificios, suscitar la participación de todos y articular las medidas de urgencia y las de largo plazo. En relación con estos principios, destacan: 1) El valor indispensable de la confianza, que debe renovarse siempre; que permite creer en la buena fe del otro, "aun si, en las dificultades, no puede mantener sus compromisos". 2) La afirmación de que es preciso tener en cuenta "la prioridad de las poblaciones más indefensas". 3) La definición del rol de la lglesia: "En estos nuevos campos éticos, la lglesia es interpelada a fin de que puntualice las exigencias de la justicia social y de la solidaridad, frente a las situaciones de cada país ubicadas en el contexto internacional". 4) La constatación de que "para ciertos países la urgencia impone soluciones inmediatas en el marco de una ética de supervivencia". 
Se abunda en esta última idea a renglón seguido: "incapaces de satisfacer sus compromisos con sus diversos acreedores, algunos paises se encuentran al borde de la quiebra. La solidaridad internacional conduce a tomar medidas de urgencia para asegurar la supervivencia de esos paises". Se enumeran actitudes más concretas que de ahiderivan: "Una ética de supervivencia debe guiar asílos comportamientos y las decisiones; evitar las rupturas entre acreedores y deudores y las denuncias unilaterales de compromisos anteriores; respetar al deudor insolvente y no imponerle exigencias inmediatas que no podria sobrellevar; aunque legales, tales exigencias pueden ser abusivas". Notemos, aqui, que se descalifica éticamente también al deudor que rompe unilateralmente sus contratos y compromisos.

Viene después, como guía ideal, la utopía evangélica: "A partir del Evangelio, otros comportamientos deberian ser examinados, como la aceptación de moratorias, la remisión parcial o incluso total de las deudas, ayudar a los deudores a recobrar su solvencia". La magnífica utopía aparece, sobre todo, en lo de "la remisión parcial o incluso total de las deudas".

Un criterio de buen gobierno para los deudores: "Pertenece a la responsabilidad de los dirigentes de un país seguir con atención la evolución de su deuda externa a fin de evitar, por imprevisión o gestión imprudente, el tener que afrontar bruscamente semejante situación extrema" (de insolvencia).

Crítica velada a la polftica del Fondo Monetario Internacional (FMI): "No obstante, en muchos casos sus decisiones han sido mal recibidas por los paises en dificultad, sus dirigentes y la opinión pública. Estas decisiones pudieron parecer impuestas de modo autoritario y tecnocrático, al margen de una insuficiente consideración de las urgencias sociales y las especificidades de cada situación. Convendría que el diálogo y el servicio a la colectividad sean vistos como los valores que guian sus acciones".

Sobre la responsabilidad de los paises industrializados, se hace, de entrada, un llamamiento a la coparticipación, "incluso a una cierta austeridad", que "será atendido solamente si se apela a los valores de fra. ternidad y de solidaridad en vista de la paz y del desarrollo". Se señalan, después, algunos campos especificos de esa responsabilidad:

1) "Una reactivación durable y sostenida del crecimiento en los paises industrializados ayudará a la economía mundial a salir de la crisis, y a los paises endeudados a hacer frente a las obligaciones de su deuda a medio y largo plazo sin comprometer demasiado su propio desarrolio". Digamos que este punto de vista está totalmente de acuerdo con el de los mejores economistas a nivel internacional.

2) Desarmar el proteccionismo. "Los países industrializados deben renunciar a las medidas de proteccionismo que crearian dificultades a las exportaciones de los paises en desarrollo, y esto favorecerá sus posibilidades econórnicas, sobre todo si los conocimientos técnicos 
son compartidos". Es el GATT el foro mundial apropiado para la lucha antiproteccionista y la expansión generalizada del comercio internacional.

3) Rebajar los tipos de interés: "Las tasas de interés monetario, practicadas por los paises industrializados son elevadas y dificultan el reembolso de la deuda en los países en desarrollo. Una coordinación de las políticas financieras y monetarias de los paises industrializados permitirá rebajarlas a un nive/ razonable y evitar las fluctuaciones erráticas de las tasas de cambio". Creemos que en el tema de la baja de los tipos de interés puede haber consenso entre paises ricos y paises pobres. Interesa a estos últimos la caída, para aliviar el peso de la deuda con ins* tituciones de crédito privadas, concertada de ordinario a intereses variables. Interesa también a los primeros, como medio de recuperación y reactivación de sus economias. Unicamente que hay que vencer la inflación, por solidaridad mundial, causante de las subidas.

4) "Hacer prevalecer mejor las exigencias de justicia y solidaridad internacionales, donde dominan exclusivamente los intereses nacionales". Ello en relación con el tema del comercio internacional y, muy en particular, con "la inestabilidad de los precios de las materias primas": "en concierto con todos los países y utilizando las competencias de las instituciones internacionales implicadas" (GATT, UNCTAD, FMI, Banco Mundial, etc.).

Sobre las responsabilidades de los palses en desarrollo se dice:

1) Que "aceptar la corresponsabilidad internacional significa... proceder a un examen de las causas internas que han contribuido a aumentar la deuda". Que "significa también contemplar las políticas necesarias de saneamiento a fin de aligerar, en lo que de ellos depende, el peso de la deuda, y promover su propio desarrollo".

2) Que sus recursos naturales deben ser bien administrados y valorizados sus recursos humanos.

3) Que conviene promuevan "las solidaridades entre todos los pai" ses en desarrollo que pueden concentarse, con buena razón, a nivel regional y mundial."

4) Que deben reconocerlas, las que hubiere, en el origen de su situación. Dice:" ".. los dirigentes de un país con dificultades económicas y financieras están a menudo tentados de cargar todas las responsabilidades sobre los otros países, a fin de ahorrarse explicaciones sobre sus propios comportamientos, sus errores y sus abusos, y evitar proponer cambios que los afectarian directamente. La denuncia de las injusticias, cometidas o consentidas por otros, para ser escuchada, debe acompañarse de una clarificación sobre la propia conducta".

5) Que es preciso aclarar culpabilidades propias. Escribe: "Las categorias que detentan el poder en los paises en desarrollo deben aceptar que sus comportamientos y sus eventuales responsabilidades en el endeudamiento de sus paises sean aclarados: negligencia en la instalación de estructuras adecuadas o abuso de las estructuras existentes (fraudes fiscales, corrupción, especulaciones monetarias, fuga de capi- 
tales privados....." Y cita un documento de la Congregación para la Doctrina dela Fe: "... la corrupción que, en ciertos paises, alcanza a los dirigentes y a la burocracia del Estado y que destruye toda vida social honesta. La rectitud de costumbres es condición para la salud de la sociedad".

6) Sobre la fuga de capitales: "La fuga de capitales nacionales hacia otros paises no concierne solamente a los países en desarrollo, sino que tiene consecuencias más graves para esos países cuando están endeudados, sobre todo si la fuga de capitales alcanza montos considerables". A la fuga, pues, de capitales desde los países en vías de desarrollo se la acusa, como mínimo, de insolidaridad humana.

7) Etica de los dirigentes políticos: "Los dirigentes polfticos... deben concebir su función como un servicio a la comunidad, con la preocupación de llegar a una repartición equitativa entre todos, de los bienes, los servicios, los empleos, dando la prioridad a las necesidades de los más pobres y atendiendo a las eventuales consecuencias sobre éstos de las medidas económicas y financieras que, en conciencia, creen deben tomar". El cargo político, por tanto, al servicio del interés general, sobre todo de los más pobres. Y ejemplaridad: "los mismos dirigentes adopten un estilo de vida próximo a aquel que sus conciudadanos se ven obligados a aceptar en las difíciles circunstancias del pais".

8) "Conviene movilizar todos los recursos nacionales disponibles - materiales y humanos - a fin de promover un crecimiento económico sostenido y asegurar el desarrollo del país". Este crecimiento permitirá atender más normalmente el servicio de la deuda. Y"atenderá también las necesidades de las generaciones futuras. Es un deber de solidaridad $y$ de justicia respecto de ellas".

9) Hay que abrirse al exterior, al contexto internacional, como condición indispensable para el desarrollo. Para ello, evitar la tentación del nacionalismo pretendidamente autárquico.

A propósito de los acreedores:

1) "Los Estados acreedores examinarán las condiciones de reembolso que son compatibles con la cobertura de las necesidades esen. ciales de cada deudor; es necesario dejar a cada país una suficiente capacidad de financiación para su propio crecimiento y para favorecer al mismo tiempo el uiterior reembolso de la deuda." Seria, en efecto, contraproducente extorsionar en el cobro a toda costa del plazo del próximo vencimiento, si con ello imposibilito el pago de los plazos posteriores.

2) Condonación, incluso, de la deuda: "Los Estados acreedores dedicarán una particular atención a los paises más pobres. En algunos casos, podrán convertir los préstamos en donaciones. Pero esta remisión de la deuda no debe empañar la credibilidad financiera, económica y política de los paises 'menos adelantados' y cegar nuevos flujos de capitales provenientes de los bancos".

3) De los bancos comerciales: "... esta actitud desborda la función tradicional de los bancos comerciales, al invitarlos a un discernimiento que supere los criterios de rentabilidad... de los capitales prestados. 
Pero ¿por qué no aceptarian asumir una parte de responsabilidad ante el mayor desafío de nuestro tiempo: promover el desarrollo solidario de todos los pueblos y contribuir asía la paz internacional? Todos los hombres de buena voluntad son convocados a esta tarea, cada uno según su competencia, su compromiso profesional y su sentido de solidaridad".

4) Las empresas transnacionales, "actores económicos y financieros en el campo internacional, están llamadas a la corresponsabilidady a la solidaridad, más allá de sus propios intereses".

Las organizaciones financieras multilaterales, han de dar "prioridad a las necesidades de las poblaciones más pobres". Sus dirigentes y funcionarios deberian tener "una conciencia viva de la solidaridad y de la justicia internacional que se debe promover".

En la conclusión el documento que comentamos propone el lanzamiento audaz de una especie de nuevo Plan Marshall para el desarrollo de los países más pobres. Entonces podrían pagar la deuda con mayores facilidades.

Creemos haber extraído en lo anterior la sustancia ética de Al servicio de la comunidad humana. No hay en ese escrito soluciones técnicas precisas - no es ésa la misión de la lglesia-, pero ciertamente que si sus sugerencias y criterios fueran seguidos como guias de acción y de la toma de decisiones, se solucionaria el problema de la deuda con mayor eficacia, a nuestro juicio, y, desde luego, con mayor solidaridad. 